\title{
40 ANOS DE ANPED
}

\author{
Andréa Barbosa Gouveia' \\ Márcia Denise Pletsch" \\ Maria Dilnéia Espíndola Fernandes"II (D) \\ Miriam Fabia Alves IV (D) \\ Salomão Antônio Mufarrej Hagev (D)
}

A Associação Nacional de Pós-Graduação e Pesquisa em Educação (ANPEd) comemora, em 2019, 40 anos de existência. Uma trajetória marcada pela defesa incondicional da educação pública, laica, de qualidade, democrática, inclusiva e socialmente referenciada.

Nesses 40 anos de existência, a ANPEd, enquanto entidade que representa a pós-graduação e a pesquisa em educação, tem sido protagonista da pauta educacional no país, ao demarcar um projeto de sociedade com o qual é possível construir uma educação que promova a emancipação social.

Para tanto, a ANPEd, ao organizar suas ações ao longo desses 40 anos, organiza-as sempre tendo como imperativo os resultados das pesquisas na área, que têm desvelado como a sociedade brasileira vai ao longo de sua história produzindo e reproduzindo, por meio de seu aparato educacional, como faces da mesma moeda, a exclusão social e a desigualdade econômica para imensos setores da sociedade brasileira.

Os resultados de estudos e pesquisas, por outro lado, também são propositivos e indicam possibilidades para a construção de uma sociedade mais justa e igualitária, em que o humano importa e se torna o sujeito de processos emancipatórios. $\mathrm{O}$ ponto exato onde se encontrariam os resultados de pesquisas e a ação do Estado, para a garantia do direito à educação para todos, ainda é tarefa para o devir histórico articulada ao projeto de sociedade.

Por tudo isso, ao longo desses 40 anos, o protagonismo da ANPEd na defesa da educação pública tem sido marcado por dois grandes movimentos. $\mathrm{O}$ primeiro pode ser vislumbrado na ANPEd enquanto entidade-instituição que opera mu-

\footnotetext{
'Universidade Federal do Paraná, Curitiba, PR, Brasil.

"Universidade Federal Rural do Rio de Janeiro, Nova Iguaçu, RJ, Brasil.

"'Universidade Federal do Mato Grosso do Sul, Campo Grande, MS, Brasil.

IVUniversidade Federal de Goiás, Goiânia, GO, Brasil.

vUniversidade Federal do Pará, Belém, PA, Brasil.
} 
danças internas para responder a contradições, tensões, desafios e perspectivas que lhe são próprios no campo da pós-graduação e pesquisa em educação. Para propor um projeto de sociedade e consequente projeto de educação e responder a eles, a ANPEd na atualidade se organiza em espaços de decisões e interlocuções de 23 grupos de trabalhos (GTs), no Fórum dos Coordenadores de Pós-Graduação (Forpred) e no Fórum de Editores de Periódicos (Fepae). Mediante essas instâncias de decisão política, a ANPEd acumula e ganha capilaridade para construir seu segundo movimento, a atuação na sociedade. Nesse sentido, essa atuação destaca-se por propor e influenciar as decisões sobre os rumos que a sociedade precisa tomar no que tange ao projeto educacional.

Ao considerar essa trajetória, no decorrer desses 40 anos, a ANPEd esteve presente em todos os momentos da vida nacional, com base em uma agenda que lhe é própria e interferindo propositivamente no projeto educacional do país. A ANPEd também assume papel importante na disputa de um projeto formativo, especialmente quando a educação da maioria é colocada em risco e se fazem necessários a denúncia, a disputa, o encontro com os movimentos progressistas que defendem a democracia e a justiça social.

Por tudo isso, foi vital a presença da ANPEd no processo constituinte com o Fórum Nacional em Defesa da Escola Pública (FNDE), quando a Constituição Federal de 1988 resultou na mais alta cobertura de um padrão de direito à educação que se tem história no país.

Desde então, o desafio tem sido manter o direito à educação, mediante o padrão concebido pela Constituição Federal de 1988, ao longo de governos que têm se sucedido no contexto democrático brasileiro, mas não só: em contexto federativo também, em que se materializam políticas educacionais com alto grau de descentralização e intensa assimetria econômico-política entre os entes federativos. Por tudo isso, a indução da União tem muita força no que concerne à materialidade da política educacional, tendo como imperativo o direito à educação, e se instaura como um espaço importante na disputa da política.

A ANPEd sempre teve claro o fato de que a uma concepção de Estado corresponde uma concepção de educação. Por isso mesmo, diante do Estado neoliberal que se anunciou logo depois de promulgada a Constituição Federal de 1988, seria necessário disputar a concepção de direito à educação definida naquela Carta Magna, fiadora do pacto federativo brasileiro. Tal disputa se daria em torno da amplitude que o direito à educação assumiria (ou não) por meio da aprovação da nova Lei de Diretrizes e Bases da Educação Nacional (LDB), a legislação infraconstitucional do setor. Foi intensa e árdua tal disputa e encerrada com uma LDB minimalista, aquém daquele direito à educação impresso na Constituição.

Novas disputas, tensões, contradições, conflitos e perspectivas têm se delineado na conjuntura desde então. O início do século XXI foi marcado, principalmente a partir de 2003, por novas perspectivas para o direito à educação. O período esteve marcado por outra perspectiva de sociabilidade e algumas inovações na relação entre sociedade e Estado. Sobretudo, foi um tempo de integração, de pertencimento de contingentes populacionais na esfera do Estado de direito democrático social que se inaugurou e que se alastrou na educação e para além dela. Foi o período marcado 
pela ampliação ao direito à educação que se materializou pela política educacional e que teve como ponto culminante a elaboração e aprovação de um novo Plano Nacional de Educação (PNE).

O novo PNE diferenciou-se dos anteriores, tanto pela metodologia de sua construção quanto pela síntese expressa para a sociedade depois de sua aprovação. Com efeito, sua síntese, expressa na Lei $n^{\circ}$ 13.005/14, apresentou o consenso social possível entre sociedade e Estado brasileiro sobre o que é o direito à educação. Consenso que reafirmou, principalmente, que a sociedade brasileira precisaria ampliar a oferta e, em consequência, o financiamento da educação para o alcance de um novo patamar de civilização.

Durante todo esse período, a ANPEd participou ativamente da disputa da política educacional, atuando crítica e propositivamente na garantia do direito à educação no poder executivo, no parlamento brasileiro, participando do Fórum Nacional de Educação e de diferentes espaços de atuação coletiva em prol de um projeto de nação mais democrática e mais justa.

A conjuntura que se iniciou em 2015, com o processo de impedimento jurídico-midiático-parlamentar contra a presidenta Dilma Rousseff, legitimamente eleita, fez que com ruísse o pacto educacional recentemente construído em torno do PNE. Desde então, as medidas tomadas no campo educacional cada vez mais restringem o direito à educação, sendo emblemática e paradigmática para tal a aprovação da Emenda Constitucional no 95/2016.

Mas não só. A conjuntura político-eleitoral do último período, que culminou com a vitória de forças conservadoras e fundamentalistas tanto no executivo federal, no parlamento, quanto também nos poderes locais, vem impondo uma agenda de restrições de direitos de toda ordem. Entre os ataques aos direitos sociais que objetivam a construção de uma nova ordem social, muitos já estão manifestos e ganham concretude por medidas legais. Outros ainda estão em curso e vão sendo rapidamente vinculados pela grande imprensa, como é o caso da possibilidade de desvincular totalmente os recursos da educação, o que, por só, já constrói um cenário de instabilidades. No âmbito da ciência e da pesquisa, os cortes nas condições de financiamento do Conselho Nacional de Desenvolvimento Científico e Tecnológico (CNPq) e da Coordenação de Aperfeiçoamento de Pessoal de Nível Superior (Capes) evidenciam os efeitos da política de austeridade fiscal que pode comprometer, agora, o futuro da nação. Grave momento para as ciências, grave momento para a Amazônia e o meio ambiente, grave momento para a educação.

A ANPEd tem se posicionado e denunciado também a ação de movimentos ultraconservadores que querem tirar de Paulo Freire o título de Patrono da Educação Brasileira, educador fundamental para a construção de uma educação comprometida com a justiça, a igualdade e o respeito à vida humana. Em todas as suas ações, tem buscado interlocuções diversas com o imperativo de defender o direito à educação para todos, laica, democrática, pública e de qualidade socialmente referenciada. E mais, tem se posicionado em defesa de uma política a favor do direito de viver dos cidadãos e da garantia dos direitos sociais como condição para uma vida digna.

Este dossiê é mais uma ação nessa direção. Ao mesmo tempo que ele expressa a luta da ANPEd ao longo de seus 40 anos de existência, também se impõe, nesse 
momento histórico, enquanto radicalidade crítica a um projeto de desmonte da nação. Os artigos apresentados no dossiê pretendem refletir sobre aspectos da organização da ANPEd como associação científica e da pesquisa no campo educacional e ainda das tessituras que permeiam a organização de uma associação de pesquisadores. Em meio a esse cenário tão desafiador, o dossiê mostra-se como esperança no sentido da certeza de que ciência, educação e organização dos pesquisadores se fazem nos encontros e nos diálogos. A resposta que os pesquisadores deram ao chamado para reflexão do dossiê "ANPEd 40 anos: a construção de resistências criativas na pesquisa e na pós-graduação para a longevidade da relação entre educação e democracia" nos revela essa perspectiva de resistência pelo diálogo e pela capacidade de compreender nossa história para construir as possibilidades de futuro.

O primeiro texto que compõe o dossiê, de Maria Antonia de Souza, da Universidade Estadual de Ponta Grossa, intitula-se "ANPEd: rumo a meio século de lutas por educação democrática", no qual a autora nos convida a um balanço sobre esses quase 40 anos da associação. Baseada nos conceitos de sociedade civil e de democracia, a autora visita os documentos da entidade e traça uma interessante trajetória tendo em vista os temas das reuniões nacionais e chama-nos a continuar construindo conhecimento por intermédio do diálogo e da resistência.

O segundo artigo apresentado no dossiê, intitulado "A produção científica dos coordenadores do GT Currículo da Associação Nacional de Pós-graduação e Pesquisa em Educação (ANPEd): opções teórico-metodológicas”, de Cleide Carvalho Matos, da Universidade Federal do Pará, Campus de Breves, nos convida a uma bela reflexão sobre a organização de um GT na ANPEd, que poderá instigar ponderações sobre a organização dos demais GTs da ANPEd. Pela análise do papel de liderança acadêmica, que as coordenações de GT no campo do currículo representam na área, o artigo permite pensar a respeito da ideia de campo de disputas do conhecimento e acerca da vitalidade dessa forma de organização da nossa associação.

O terceiro artigo novamente coloca luz sobre a organização de um GT, intitulado "Pesquisa em educação de jovens e adultos: memórias e ações na constituição do direito à educação para todos", escrito por Jane Paiva, da Universidade do Estado do Rio de Janeiro, Sergio Haddad, da Universidade de Caxias do Sul, e Leôncio José Gomes Soares, da Universidade Federal de Minas Gerais. Os autores mergulham no campo de produção sobre a educação de jovens e adultos, refletem quanto às demandas de pesquisa na área, apresentando desafios ao próprio GT para os pesquisadores individualmente e para interlocuções entre diferentes GTs dentro da ANPEd, e também no tocante às fronteiras do conhecimento atual sobre educação para todos e todas e aos desafios para o futuro.

O quarto artigo, intitulado "Os boletins da ANPEd: das possibilidades de problematização das questões educacionais para além dos espaços acadêmicos”, de Helena Maria Ferreira e de Francine de Paulo Martins Lima, ambas da Universidade Federal de Lavras, propõe uma reflexão com por intermédio da análise da política de comunicação da ANPEd expressa nos boletins, problematizando o papel formativo e de enfrentamento desse instrumento no debate educacional e político da sociedade brasileira. 
Com um olhar sobre a produção do conhecimento no âmbito dos programas de pós-graduação, ultrapassando, portanto, a estrutura da ANPEd, mas ainda pensando na fecundidade da pesquisa em educação no Brasil, está o quinto artigo. De autoria de Mônica Castagna Molina, da Universidade de Brasília, em parceira com Maria Isabel Antunes-Rocha e Maria de Fátima Almeida Martins, professoras da Universidade Federal de Minas Gerais, intitulado “A produção do conhecimento na licenciatura em Educação do Campo: desafios e possibilidades para o fortalecimento da educação do campo", o artigo evidencia a produção nas regiões do país, além do desafio de a produção de conhecimento nesse campo primar pela articulação entre a formação construída na prática dos movimentos sociais do campo e as reflexões no âmbito da pesquisa de ponta realizada no seio dos programas de pós-graduação, lócus fundamental da produção científica brasileira.

A articulação da ANPEd com outros movimentos sociais é parte integrante de sua identidade. Nesse sentido, faz-se muito pertinente o dossiê também abranger reflexões sobre a vitalidade da organização recente da sociedade brasileira. $\mathrm{O}$ sexto artigo, intitulado "Rede Escola Pública e Universidade: produção do conhecimento para/com as lutas educacionais", de autoria de Débora Cristina Goulart, da Universidade Federal de Guarulhos, e de Fernando Luiz Cássio Silva e Salomão Barros Ximenes, da Universidade Federal do $\mathrm{ABC}$, convida à reflexão no que concerne a esse encontro entre pesquisa, escola, movimento estudantil e sistema de justiça pela análise do contexto das ocupações da escolas paulistas protagonizadas pelo movimento estudantil secundarista e as consequências desse movimento para a ação da justiça e para a proposição de alternativas a fim de colocar o conhecimento produzido na universidade em diálogo com o contexto urgente dos embates das políticas educacionais.

Finalmente, o último artigo que compõe o dossiê novamente propõe pensar a ANPEd e as articulações no campo da resistência às políticas que descontroem o direito à educação. $\mathrm{O}$ artigo intitulado "Educação e democracia: Base Nacional Comum Curricular e novo ensino médio sob a ótica de entidades acadêmicas da área educacional", de Marilda de Oliveira Costa e Leonardo Almeida da Silva, ambos da Universidade do Estado de Mato Grosso, coloca luz no processo de resistência a mudanças bruscas na política educacional nacional. $\mathrm{O}$ foco do debate é a produção das posições da ANPEd, da Associação Brasileira de Currículo (ABdC) e da Associação Nacional pela Formação dos Profissionais da Educação (Anfope). Mediante notas específicas emitidas pelas entidades e notas conjuntas, os autores mapeiam a crítica acadêmica à reforma educacional recente e evidenciam como a especialização da pesquisa pode contribuir para a análise profunda das políticas no processo de disputa.

Qualquer editorial sempre fica aquém da potência dos debates de cada artigo, porém, além da qualidade da produção apresentada neste dossiê e do convite à leitura, procurou-se salientar as possibilidades abertas por esse grande coletivo de pesquisadores brasileiros que constitui a área da educação e a ANPEd. O destaque ao vínculo institucional dos autores quer ser mais que uma formalidade e ressaltar o fato de que a pesquisa científica é produzida nas diferentes regiões do país, e a ANPEd representa esse espaço fértil para a reunião dos pesquisadores e a interlo- 
cução com sua produção. Nesse diálogo entre vários pesquisadores, com diversidade de temas e de abordagens, a ANPEd tem se feito forte e fortalecido a divulgação científica e o diálogo crítico.

Este editorial é um convite à leitura e um convite à participação nessa pungente associação!

Rio de Janeiro, outubro de 2019. 